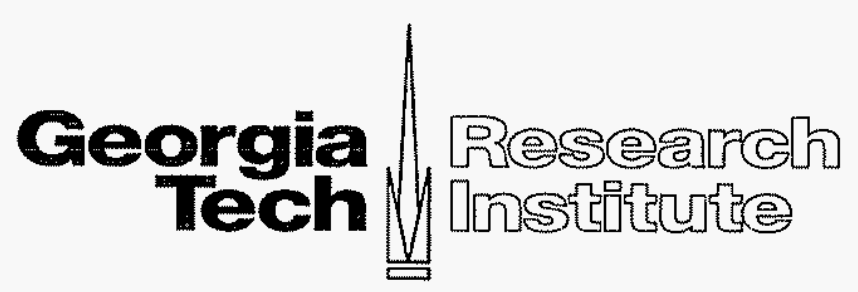

\title{
CONTINUED DEVELOPMENT AND IMPROVEMENT OF PNEUMATIC
} HEAVY VEHICLES, PHASE VI

FINAL REPOR'T for PHASE VI

Period Ending July 15, 2005

\author{
DE-AC26-O2EE50691 \\ CONTRACT NO. PE-AF03-02EE50691.
}

GTRI Project No. A-6935

\author{
Prepared for: \\ U. S. Department of Energy, HQ, \\ Attn: Dr. Sid Diamond, PhD \\ Forrestal Bldg (5G-064) \\ Office of FreedomCar and Vehicle Technologies (EERE) \\ 1000 Independence Ave., SW \\ Washington, DC 20585
}

\author{
Prepared by: \\ Robert J. Englar, Principal Research Engineer \\ Aerospace, Transportation and Advanced Systems Laboratory \\ Georgia Tech Research Institute \\ Georgia Institute of Technology \\ Atlanta, GA 30332-0844
}

July 13,2005 


\title{
Continued Development and Improvement of Pneumatic Heavy Vehicles, Phase VI $\sim$ Final Report for Period Ending July 15, 2005
}

\section{Principal Investigator:}

\author{
Robert J. Englar, Principal Research Engineer \\ Georgia Tech Research Institute \\ Aerospace, Transportation \& Advanced Systems Laboratory \\ CCRF, Code 0844 \\ Atlanta, GA 30332-0844 \\ (770) $528-3222$, Office \\ (770) 528-7077, Fax \\ (770) 528-7586, Wind Tunnel \\ bob.englar@gtri.gatech.edu
}

\section{Program Objective:}

The objective of this applied research effort led by Georgia Tech Research Institute is the application of pneumatic aerodynamic technology previously developed and patented by us to the design of an appropriate Heavy Vehicle (HV) tractor-trailer configuration, and experimental confirmation of this pneumatic configuration's improved aerodynamic characteristics. In Phases I to IV of our previous DOE program (Reference 1), GTRI has developed, patented, wind-tunnel tested and road-tested blown aerodynamic devices for Pneumatic Heavy Vehicles (PHVs) and Pneumatic Sports Utility Vehicles (PSUVs). To further advance these pneumatic technologies towards HV and SUV applications, additional Phase V tasks were included in the first year of a continuing DOE program (Reference 2). Based on the results of the Phase IV full-scale test programs, these Phase V tasks extended the application of pneumatic aerodynamics to include: further economy and performance improvements; increased aerodynamic stability and control; and safety of operation of Pneumatic HVs. Continued development of a Pneumatic SUV was also conducted during the Phase V program. Phase V was completed in July, 2003; its positive results towards development and confirmation of this pneumatic technology are reported in References 3 and 4.

The current Phase VI of this program was incrementally funded by DOE in order to continue this technology development towards a second fuel economy test on the Pneumatic Heavy Vehicle. The objectives of this current Phase VI research and development effort (Ref, 5) fall into two categories: (1) develop improved pneumatic aerodynamic technology and configurations on smaller-scale models of the advanced Pneumatic Heavy Vehicle (PHV); and based on these findings, (2) re-design, modify, and re-test the modified full-scale PHV test vehicle. This second objective includes conduct of an on-road preliminary road test of this configuration to prepare it for a second series of SAE Type-II fuel economy evaluations, as described in Ref. 5. Both objectives are based on the pneumatic technology already developed and confirmed for DOE OHVT/OAAT in Phases I-V. This new Phase VI effort was initiated by contract amendment to the Phase V effort using carryover FY02 funds. This were conducted under a new and distinct project number, GTRI Project A-69.35, separate from the Phase I-IV program. However, the two programs are closely integrated, and thus Phase VI continues with the previous program and goals.

Start Date: July 15, 2002 (Phase V, FY02)

July 15, 2003 (Phase VI,FY03, FY04)

Duration: 12 months Duration: 24 months 


\section{Current Progress:}

The reported effort represents work performed in Phase VI of this program. This effort was conducted by the GTRI Aerospace, Transportation \& Advanced Systems Lab for the Department of Energy's Office of FreedomCar and Vehicle Technologies through National Energy Technology Laboratory (NETL) contracting. The following FY03 efforts (Tasks 1-4 below) were conducted as a continuation of the previous GTRI efforts for DOE (References 1 and 2), and they build on that Phase I-V work. Task 5 is a continuation of Phase VI into FY04. All five tasks below were completed by the end of Quarter 10, January 15, 2005. They are briefly summarized below for program management review. This FYO4-finded effort is thus now complete. For a more detailed technical summary of this completed effort, see page 6 .

Phase VI, Tasks 1 and 2-Tasks 1 and 2 for the FY03 Phase VI program included modification of our existing 0.065 -scale Pneumatic Heavy Vehicle (PHV) blown wind-tunnel model to a more current tractor and improved blown trailer configurations; and assistance to NASA personnel in preparation for a future high-Reynolds-number wind-tunnel test of this blowing configuration. These were previously completed and reported, and are summarized as:

Task 1: A final blown Pneumatic Heavy Vehicle model configuration which was determined from the above evaluations has experimentally confirmed in the GTRI wind tunnel that $C_{D}$ was reduced $31 \%$ at a blowing coefficient of $C \mu=0.04-0.05$ relative to the unblown stock baseline configuration. Higher $C_{D}$ reductions were recorded if higher blowing $C \mu$ values were available for the vehicle. Thus this Task 1 wind-tunnel evaluation provided a "real-world" configuration that is capable of very significant drag reduction, which should correspond to significant fuel economy increase at $60-65 \mathrm{mph}$ highway speeds. These tests also confirmed (see Figure 11 of Reference 7) the ability to provide yawing moment to counteract side winds and also to provide directional stability for these large flat-sided vehicles. A valuable lesson from these tests was the considerable interference effects (separated flow fields and/or reversed flow) produced by all the mechanical components on the trailer underside. It is very important to account for and treat the underbody of the entire vehicle!

Task 2: Assist/Guide NASA Ames in Higher-Reynolds-Number Testing of Pneumatic Configurations. This task was completed in Quarter 6; see Ref. 6.

\section{Phase VI, Tasks 3 and 4, (FY03 funding carryover into FY04):}

Task 3: Re-design the Full-Scale PHV Test Vehicle: Based on the results of Task 1 and lessons learned from the earlier tests of the revised PHV tunnel model, we included the abovedetermined improvements in the re-design of the PHV road-test vehicle. Team members who conducted this included GTRI and Novatek, Inc., which developed and built the initial blown test trailer. We then completed actual modification of the full-scale test trailer into this new configuration.

During this modification of the track-test vehicle, the new aerodynamic configuration elements from the tunnel test were fabricated and installed (Figure 1). After final assembly of these components, the full-size test vehicle closely resembled the tunnel test configuration of Task 1 to allow it to produce on-road drag reduction similar to that indicated by the tunnel-test results. 


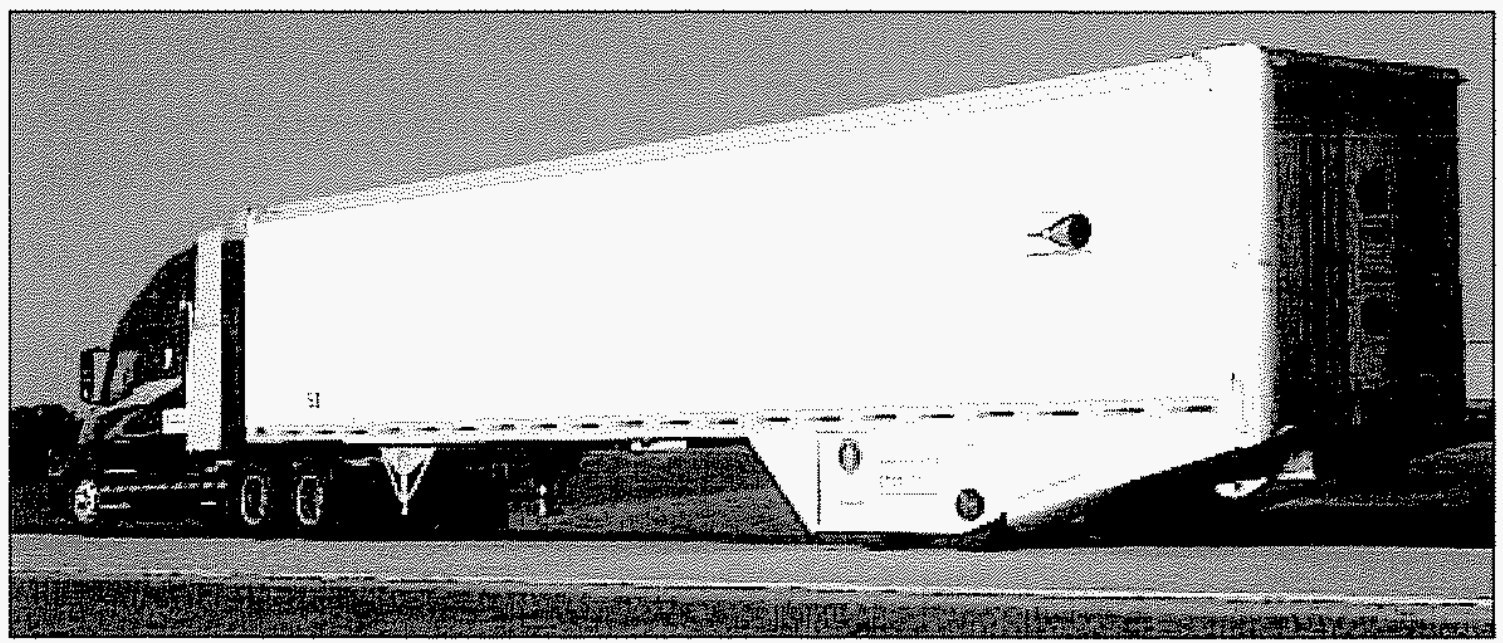

Figure 1- Modified Trailer during on-track SAE Fuel Economy Test II

Task 4: Conduct Preliminary Road Tests of Modified PHV Test Vehicle: The modified PHV test truck was transported by our teammate Volvo to its test facility. We then conducted preliminary on-road tests of this new PHV configuration, similar to our Tuning Tests 1 and 2 previously conducted at the Volvo facility during the Reference 1 program. These tests, as reported in Refs. 8 and 9, unofficially showed up to 18\% Fuel Economy Increase (FEI) at higher blowing, or $12-15 \%$ at a moderate blowing value of $\mathrm{C} \mu=0.025$.

Phase VI, Task 5, (FY04 funding): Our Reference 10 proposal resulted in FY04 funding to conduct our second SAE Type-II fuel economy test on the PHV test vehicle at the Transportation Research Center in Ohio. Figure 1 shows the pneumatic test vehicle at the TRC test site. A summary of the results of these fuel-economy tests is shown in Figure 2 (from Refs. 8,9 and 11), which presents measured fuel economy increase $(\% \mathrm{FEI}=$ percent miles/gallon increase over the baseline stock vehicle) as a function of jet blowing momentum coefficient, $\mathrm{C} \mu$. The PHV test configuration yields up to $11-12 \% \mathrm{FEI}$ (upper curves), with $4-5 \% \mathrm{FEI}$ coming directly from blowing alone (lower curves) and a good portion of the remaining \%FEI resulting from the curved aft surfaces and aft geometry improvements (an integral and necessary part of the PHV technology). This figure also shows that when the fuel used by the onboard test configuration blowers is accounted for (dashed curves), the total configuration still yields up to 8-9\%FEI. Best performance is seen at moderate blowing values of $\mathrm{C} \mu=0.02$ to 0.03 . Thus, future consideration needs to be given to the means in which this moderate onboard blowing air is provided in order to afford maximum efficiency for this drag-reduction system. For the US Heavy Vehicle trucking fleet, a $1 \% \mathrm{FEI}$ represents approximately 200 million gallons of diesel fuel saved per year, so the above test results are quite significant, up to 1.6 to 1.8 billion gallons saved per year.

Further details of this PHV fuel-economy test are provided in Refs. 8, 9, and 11. A summary of the project and its results, plus more photos of the test vehicle, is seen in the GTRI news released dated January 5, 2005, which can be found at:

http://gtresearchnews.gatech.edu/newsrelease/truckfuel.htm 


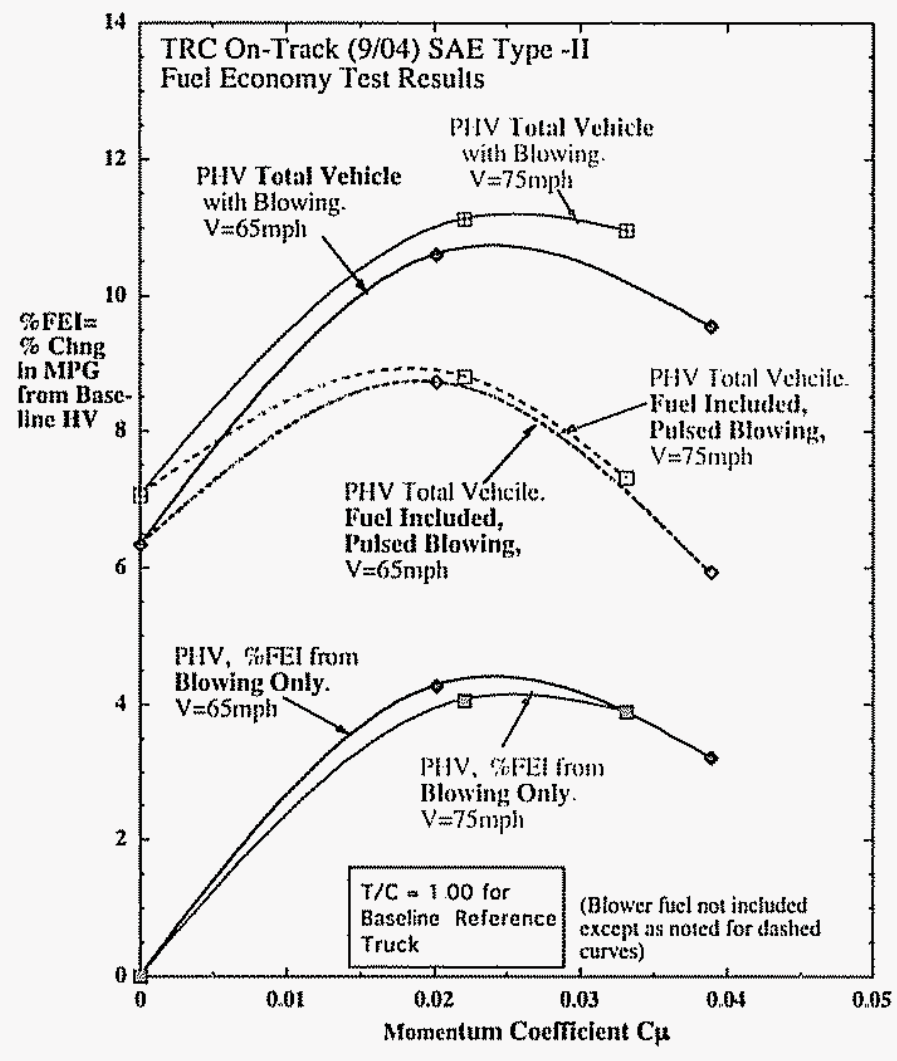

Figure 2- SAE Type-II fuel economy results for the new PHV test truck configuration

Phase VI Summary: Details of the above results, and thus of the entire Phase VI program, will be presented as a formal technical paper (Ref. 11) at the SAE 2005 Commercial Vehicle Engineering Conference in Chicago in November, 2005. That paper (as recently submitted to SAE in draft form) is presented herein as summary details in Appendix A.

Issues and Challenges: We have now completed all 5 contracted tasks for Phase VI of this DOE-sponsored research project on truck aerodynamic drag reduction, employing FY02, FY03 and FY04 funding. We have successfully demonstrated very significant drag coefficient reduction (31\% or more was measured, depending on available blowing) on smaller-scale wind-tunnel models of the GTRI Pneumatic Heavy Vehicle concept. We have also demonstrated during official SAE Type-II fuel economy tests that these aerodynamic devices can yield very significant improvements in onroad fuel efficiency increase (up to $12 \% \mathrm{FEI}$ ) for the US trucking fleet's Heavy Vehicles. The challenge that now remains is to successfully convey this technology to the US trucking industry in such a manner that they will readily adapt it to their operational fleet vehicles to take advantage of the fuel-saving and safety-of-operation capabilities this provides to them. We thus need to optimize the means by which the blowing air for the pneumatic system is supplied, and also to optimize the aerodynamic system configuration, likely by the use of further tunnel testing guided by Computational Fluid Dynamics (CFD) predictions of this viscous-fluid-flow aerodynamic phenomenon which empowers the Pneumatic Heavy Vehicle. Proposed for FY05 funding (Ref. 12), these funds have not yet been allocated to GTRI to conduct this undertaking. However, these are expected to be initiated soon in conjunction with the CFD work of Dr. David Pointer at Argonne National Lab. We have recently been discussing this technology with HV industry parts manufacturers, who have asked to license it from GTRI and to employ further GTRI efforts in engineering and development of production HV add-ons with blowing. 
Publications: A list of all publications written during this PHV project for DOE was provided to LLNL on January 10, 2005 at the request of Dr. Sid Diamond. Recent technical publications are provided in the Reference List of this final report as Refs. 8, 9, 11,13,14, 15, 16, 17, 18, 19, 20, 21, and 22. Three of these technical papers (Refs. 15, 16, and 17) have also been submitted for inclusion in an AlAA Proceedings document on aerodynamic applications of this pneumatic technology.

The SAE paper of Reference 18 was written about tire aerodynamic research conducted by GTRI for Michelin Americas R\&D Corporation, which used (with DOE permission) the PHV windtunnel scale models from this current project as a baseline configuration. (No Michelin test costs were borne by the DOE project.). Recent meetings have occurred with Michelin representatives to further the study of tire/wheel aerodynamics from both fuel-economy and safety-of-operation (side winds and gusts) issues. It is hoped that DOE will also acquire interest in this additional new aerodynamic means of improved tires and suspensions to increase HV fuel economy.

Additional contacts from the HV community have occurred (including discussions with Volvo Technology of America; Great Dane Trailers; Aeroficient; J. Hoelzer, Inc.; ETS Technologies; Peterbilt; Hendrickson International; the Boler Company; etc.).

Budget Information (end of June, 2005): Funds planned and expended for this effort are shown below, which includes expenditures by the GTRI team, as well as encumbrances by subcontractors Novatek, Inc. and Volvo. Also shown here is funding for both the FY02 (Phase V) and FY03 (Phase VI) efforts, as these are both part of the same fixed-price contract in FY04. No new expenditures have occurred since the last quarterly report (No. 11) because all of the funding for this fixed-price program has been expended, and all contracted tasks have been completed. The current project end date is July $15,2005$.

The following summary financial data are supplied for this project:

FY02 DOE Funds Carried over into FY03 \$307K

FY03 DOE Funds Carried over into FY04 \$275K

FY04 DOE Funds Allocated to Date to this Project (\$225K)

Costs to Date in FY04 Funds (as of 6/30/2005) $\$ 225 \mathrm{~K}$

FY02, FY03 \& FY04 Funds (spent as of 6/30/2005) \$807K

FY05 Funds Allocated to Date $\$ 0 \mathrm{~K}$

FY05 Funds Spent to Date $\quad \$ 0 \mathrm{~K}$

No FY05 funding has yet been allocated to GTRI for continuation of this project; this is currently awaiting DOE funding go-ahead in response to our Ref. 12 proposal.

Key Deliverables and Milestone Status: We have now completed all the fixed-price contractual efforts in Tasks 1,2,3,4 and 5 of this Phase VI effort. These were reported in our DOE FY04 Final Report, Ref. 9. We have also expended all allocated research contract funds for this project through and including FY04 funding. This Final Report thus ends the Phase VI GTRI team effort for DOE from FY02 through FY04.

\section{References:}

1. Oak Ridge National Lab, DOE Contract 4500001555, "Development and Evaluation Of Pneumatic Aerodynamic Devices to Improve the Performance, Economics, Stability and Safety Of Heavy Vehicles," Phases I-IV, Dec. 12, 1998 to Feb. 14, 2003. 
2. Englar, Robert J., "Aerodynamic Devices to Improve the Performance, Economy and Stability \& Control of Heavy Vehicles and SUVs, Phase V," GTRI Proposal ATASL-02-1604, June 13, 2002.

3. "DOE Project on Heavy Vehicle Aerodynamic Drag," FY2003 Heavy Vehicle Systems Final Report, October, 2003.

4. Englar, R. J., "Drag Reduction, Safety Enhancement and Performance Improvement of Heavy Vehicles and SUVs Using Advance Aerodynamic Technology," SAE Paper 2003-01-3378, SAE 2003 International Truck and Bus Meeting, November 10-12, 2003, Fort Worth TX.

5. Englar, Robert J., "Continued Development and Improvement of Pneumatic Heavy Vehicles, Phase VI". GTRI Proposal ATASL-03-1601, Rev. C, March 13, 2003.

6. Englar, Robert J., "Continued Development and Improvement of Pneumatic Heavy Vehicles, Phase VI," GTRI Quarterly Report No. 6, October 16, 2003 to January 15, 2004", January 15, 2004.

7. Englar, Robert J., "Continued Development and Improvement of Pneumatic Heavy Vehicles, Phase VI," GTRI Quarterly Report No. 7, January 16, 2004 to April 15, 2004", January 15, 2004.

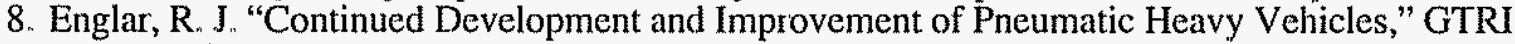
FY04 Final Report and Quarterly Report No. 9, October 15, 2004

9. Englar, R. J. "Continued Development and Improvement of Pneumatic Heavy Vehicles," Paper x, DOE FY2004 Annual Report, 2005.

10. Englar, R.J., GTRI Proposal ATASL-04-1607, Rev. B, "Continued Development of Pneumatic Heavy Vehicles, Phase VII, FY04," April 2, 2004.

11. Englar, R. J. "Pneumatic Aerodynamics for Drag Reduction, Safety and Stability Increase for Heavy Vehicles," Draft paper SAE 2005-01-05CV-083 for SAE 2005 Commercial Vehicle Engineering Conference, Chicago, November 1-3, 2005.

12. Englar, R. J., "Continued Development of Pneumatic Heavy Vehicles Using CFD Analytical Methods," GTRI Proposal ATASL-06-1807, July 8, 2005.

13. Toon, John, "Low-Drag Trucks," in GTRI Research Horizons, Winter 2005, Vol 22, No.2.

14. "Trucks get fuel efficiency boost," InTech Magazine, March, 2005.

15. Gaeta, R. G. "Pneumatically Augmented Aerodynamic Heat Exchanger," presented at the NASA/ONR 2004 Circulation Control Workshop, March 16-17, 2004.

16. Englar, R. J., "The Application of Pneumatic Aerodynamic Technology to Improve Performance and Control of Advanced Automotive Vehicles," presented at the NASA/ONR 2004 Circulation Control Workshop, March 16-17, 2004.

17. Burdges K. B., "Design and Fabrication of Circulation Control Test Articles," presented at the NASA/ONR 2004 Circulation Control Workshop, March 16-17, 2004.

18. "NASA/ONR Circulation Control Workshop Proceedings," NASA CP 2005-213509, January, 2005.

19. Englar, Robert J. and Ibrahim M. Janajreh, "Quantification of Tire Aerodynamics on Overall Heavy Truck Aerodynamics," SAE Paper 2004-01-2695, presented at SAE Commercial Vehicle Engineering Congress, Chicago, October 26-28, 2004.

20. "Aerodynamic improvements and flow control systems could boost fuel economy", The Trucker Magazine, pp 48-49, February 1, 2005.

21. "Technology- Thrifty trucks go with the flow," Science News, Jan. 29, 2005, Vol. 167, p.78.

22."More aerodynamic trucks envisioned," Livescience.com, Jan. 17, 2005, (http://www.livescience.com)

APPENDIX A, (continued on following pages)

Technical paper accepted for and to be presented at

SAE 2005 Commercial Vehicle Engineering Conference, Chicago, November 1-3, 2005 


\title{
Improved Pneumatic Aerodynamics for Drag Reduction, Fuel Economy, Safety and Stability Increase for Heavy Vehicles
}

\author{
Robert J. Englar, Principal Research Engineer \\ Georgia Tech Research Institute; Aerospace, Transportation and Advanced Systems Lab; Atlanta, GA, 30332
}

Copyright (C) 2005 SAE Intemational

\begin{abstract}
Aerodynamic drag is the major component of Heavy Vehicle (HV) resistance at typical highway speed and thus strongly impacts related fuel economy because horsepower required to overcome this drag increases as the cube of vehicle speed. In an ongoing drag-reduction program for HVs conducted for the Department of Energy, Georgia Tech Research Institute (GTRI) has been applying advanced new aerodynamic technology previously developed for aircraft which uses tangential blowing to reduce the drag generated by these bluff-based high-drag vehicles, particularly the trailer. Whereas this drag reduction can be accomplished without moving surfaces by this blown concept, it also offers the potential to increase drag for braking when needed and to overcome both the drag and destabilizing side forces due to large side winds and gusts. Windtunnel evaluations of both baseline unmodified HVs and the blown Pneumatic Heavy Vehicle (PHV) configurations have confirmed drag coefficient reductions of up to $31 \%$ below the baseline due to these new pneumatic configurations. These tunnel results have now led to a recent full scale on-track SAE Type-II fuel economy evaluation of this concept installed on a Volvo-Great Dane test vehicle combo. Test-track results have shown an $11-12 \%$ Fuel Economy Increase (FEI) for this blown vehicle, which is reduced slightly to $8-9 \% \mathrm{FEI}$ once the fuel to drive the non-optimized onboard test blowers is included. Since $1 \%$ FEI represents approximately 200 million gallons of diesel fuel saved if employed by the entire US HV fleet, optimistic promise is shown by this data; this could be increased even further with an optimized blower installed. These model-scale and full-scale results are presented in this paper, as are results showing aerodynamic braking and side-wind control resulting from slight modifications to the blown system if applied to advanced PHV configurations.
\end{abstract}

\section{INTRODUCTION}

To counteract aerodynamic drag as the major component of Heavy Vehicle (HV) resistance at highway speeds of 60-65 mph and higher, and to the improve the related fuel economy, GTRI has patented and has been developing advanced aircraft aerodynamic technology using tangential blowing to reduce that drag yielded by generally-bluff high-drag vehicles. Using the pneumatic aerodynamic technology known as Circulation Control [Ref. 1] and certain geometry changes, we have been able to reduce drag coefficient $\left(C_{D}\right)$ on simplified $\mathrm{HV}$ models by up to $45-50 \%$ (see Figure 1) during a 5 year tunnel test program for DOE [Refs. 2, 3, 4]. [However, part of this reduction was due to fairing the gap between the tractor and trailer, which may not be totally feasible due to needed clearance during

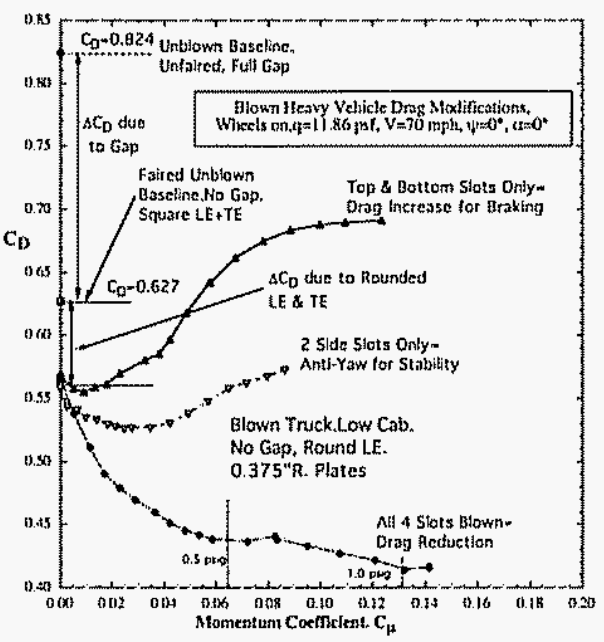

Fig. 1- Drag reduction or drag increase demonstrated by earlier GTRI generic model PHV, depending on blowing slot activated (Ref. 4) 
turns]. From Fig. 1, the tunnel-demonstrated effects confirm $23 \%$ drag reduction due only to blowing at the lower values of blowing coefficient, $\mathrm{C} \mu<0.06$, and $10-11 \%$ due only to the rounded corn -ers). In addition to drag reductions due to blowing by entrainment of separated flow and increased base pressure, a portion of this drag reduction was due to the device's fore and aft comer rounding and other improvements in the vehicle geometry. The combination of blowing and related geometry changes on only the trailer resulted in up to $31 \% C_{D}$ reduction over the baseline vehicle without gap improvement. Of further advantage, we could also increase drag (up to $35 \%$ ) as needed for braking during downhill operation by rapidly blowing select trailing-edge surfaces on the trailer without any moving parts We could also potentially reduce the huge drag increase and loss of stability which occur when an HV experiences side winds or gusts. This multi-function potential of the blown configurations is seen in the wind tunnel data of Figure 1, which were all run on a rather generic tractor-trailer model with a smooth bottom and simplified wheels /suspension. Possibly using compressed air from an $\mathrm{HV}$ tractor's turbocharger or an auxiliary engine similar to a refrigeration unit, we can thus reduce $C_{D}$ of a baseline tractor-trailer by up to $40-50 \%$ with these new pneumatic configurations, and thus fuel economy should be increased by $20-25 \%$ or more at highway speeds (or even higher percentage as speed exceeds 60-65 mph where drag then dominates).

Full-scale fuel economy tests were conducted [Refs. 3,4] during an earlier phase of our DOE program. Whereas preliminary Tuning Tests had showed unofficial Fuel Economy Increase (\%FEI) of over $15 \%$, the SAE Type-II official test-track results on a somewhat different Pneumatic HV (PHV) configuration showed measured \% $\mathrm{FEI}$ of only $4 \%-6 \%$ (very respectable, but less than expected based on the above tunnel results). Since that first SAE test, the current program has thus concentrated on: determining the difference between wind-tunnel results and the less-than-expected fullscale performance; correcting the blownconfiguration problem areas; and preparing for and conducting a second fuel-economy evaluation with the improved PHV vehicle. The following sections will present those efforts on the improved model and the resulting full-scale results on the improved track-test rig.

\section{EXPERIMENTAL DETAILS and RESULTS FOR UPDATED WIND-TUNNEL MODEL}

\section{Revised Model}

Experimental wind-tunnel developments of this technology conducted on smaller-scale PHV model under previous DOE funding [Refs. 2, 3, 4, 5] had led to two full-scale Tuning Tests conducted at Volvo Truck's facilities, plus an SAE Type-II Fuel Economy Test conducted at the 7.5-mile test track at Transportation Research Center in Ohio, with the results reported above. However, the wind tunnel model employed here (the generic Ground Transportation System, GTS, configuration modified with our blowing systems, References 2 and 3) was geometrically quite different from the actual on-road and on-track test PHV configuration. This model had generated drag reductions of over $84 \%$ relative to the stock trailer configuration (Figure 1, from Ref. 5). Since the fuel economy increases from these drag reductions were found to be less on the road-test PHV vehicle than the tunnel data predicted, we returned to the tunnel this past year to determine the reasons and possible corrections on a model which we specifically modified to be very similar to the full-scale blown test truck. These results were reported in Refs. 6 and 7 , but are summarized here to demonstrate the significance of certain aerodynamic components.

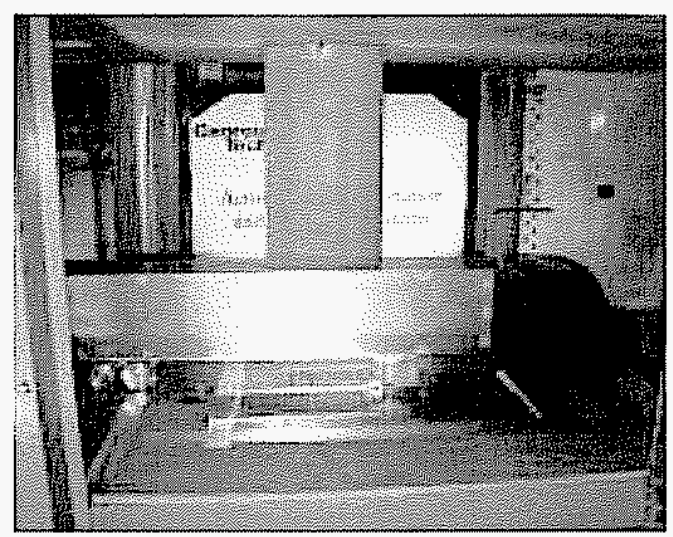

Fig. 2- Generic Conventional Model tractor with partial wheels and new PHV trailer 
The new PHV model fabricated and tested is shown in Figs. 2 and 3, where many of the new components are noted. At DOE request, we replaced the earlier generic GTS tractor with the more current Generic Conventional Model (GCM) tractor shown in Figure 2. Note that while this tractor is representative of current on-road vehicles, it has only partial cylindrical wheels hidden within aft fairings on the tractor and partial square-cornered cab extenders at the tractor/trailer gap. The new trailer has blowing surface components similar to before but covering less vertical height (the trailer floor is raised to the conventional level, not low-boy height). As Figures 2 and 3 imply, the model has many new components typical of the real test trailer:

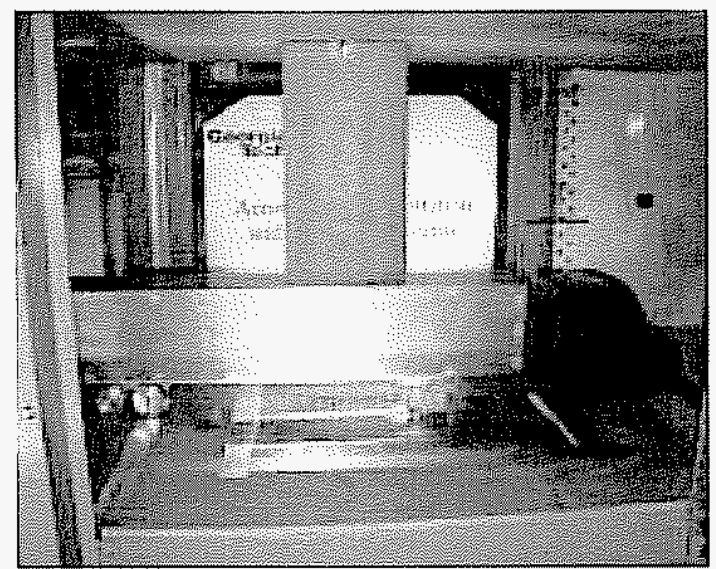

Fig. 2- Generic Conventional Model tractor with partial wheels and new PHV trailer

Trailer suspension, springs, brakes, axles, support feet (jack stand), I-beam floor rails

\section{Mirrors}

Tractor differentials, suspension

Cab gap extenders (full and $60 \%$ coverage)

Trailer rear under-ride bar, mud flaps

Stock wheels spaced 4 per axle, plus other wheel options

Figure 4 shows many of these installed on the tractor/trailer model. Details of some 325 new wind tunnel runs conducted over ranges of tunnel speed, blowing rate, yaw (side wind) angle and model configuration variations are presented in References

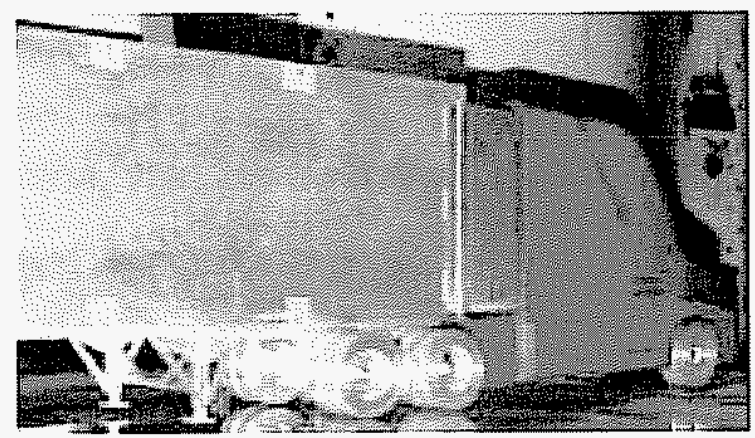

Fig. 3a- Full cab extender (CE3"), 4 stock wheels per axle, jack stands, and differentials on new model

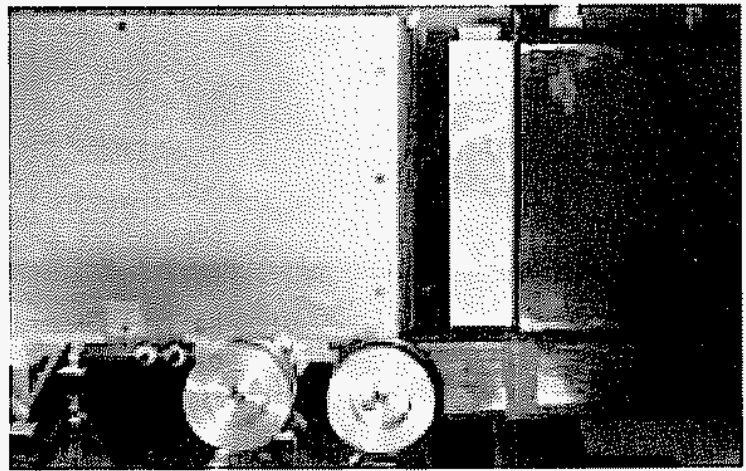

Fig. 3b- 60\%cab extender, (CE1.5")

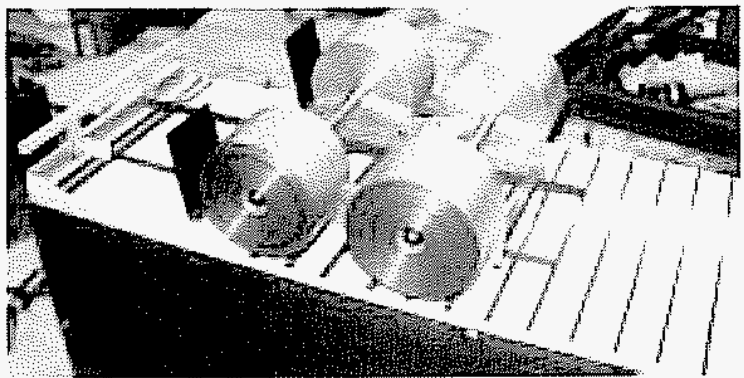

Fig. 4- New model trailer underside with double wide wheels, aft under-ride bar, under-floor Ibeams, suspension, springs, rails, and mud flaps

6 and 7 , and the most significant findings are presented below.

The importance of cab extenders in counteracting the adverse effects of asymmetric vortex shedding in the gap between tractor and trailer is shown in Figures 5 and 6 for the unblown tractor/trailer configuration. Clearly, a gap fairing is needed here (see "Full Open Gap" curves), but as the $100 \%$ full-coverage gap extenders (CE3") may not be feasible during vehicle turning, we decided on 
a 60\% gap closure (CE1.5") which produces nearly the same aero drag results as the $100 \%$ full closure but is entirely feasible ( it leaves a 16" gap on the real vehicle).

\section{Updated Wind-Tunnel Results}

Figure 7 shows the results of blowing and various components on drag reduction compared to the conventional GCM model with square leading and trailing edges on the trailer and a full open gap. Run 171 is the best blown configuration of the GTS "unrealistic" generic model from the previous tests.

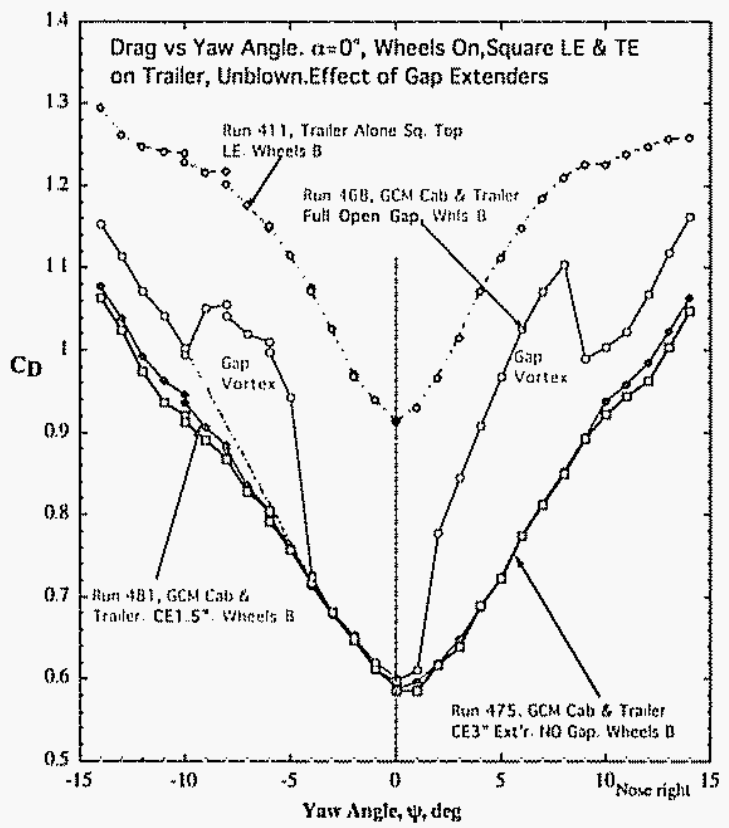

Fig. 5- Measured drag of the new trailer only (square LE \&TE) and the tractor/trailer combo at yaw angle for various gaps

The black curve (Run 585) of Fig. 7 represents the corresponding 90-deg/30-deg blown trailing edge geometry with the representative 4-peraxle wheels and suspension installed on the GCM PHV model. Initial drag reduction due to $\mathrm{C} \mu$ flattens out and then rises slightly as the wake from the wheels interferes with the jet turning, much as it did on the full-scale PHV of Ref. 4 behind the blowerengine fairing's aft-facing step. As we faired the wheels, (Run 601), the conditions improved until the new blown truck was very close to the target green curve from the previous generic tests, Run 171. This

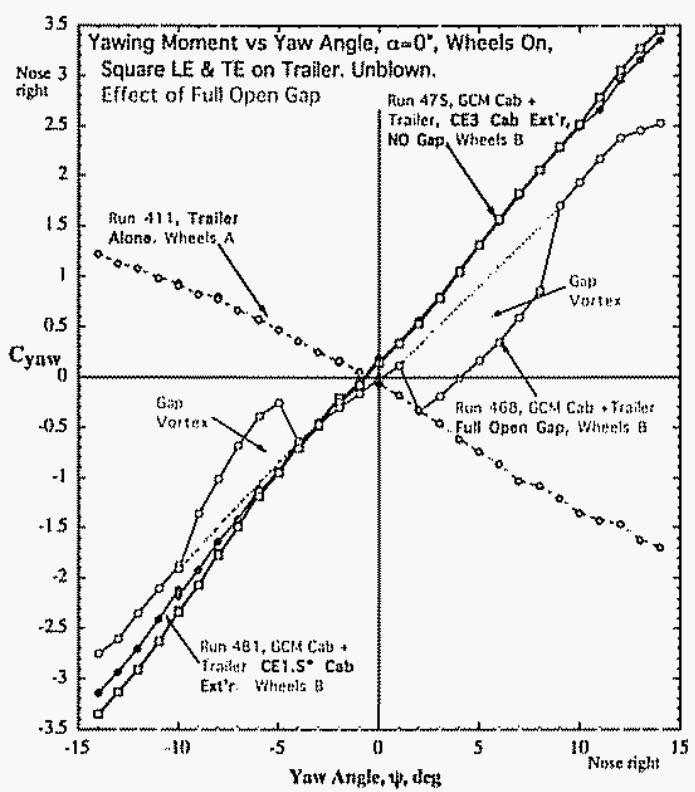

Fig. 6- Measured yawing moment of the new trailer alone and the tractor/trailer combo at yaw angle for various gaps

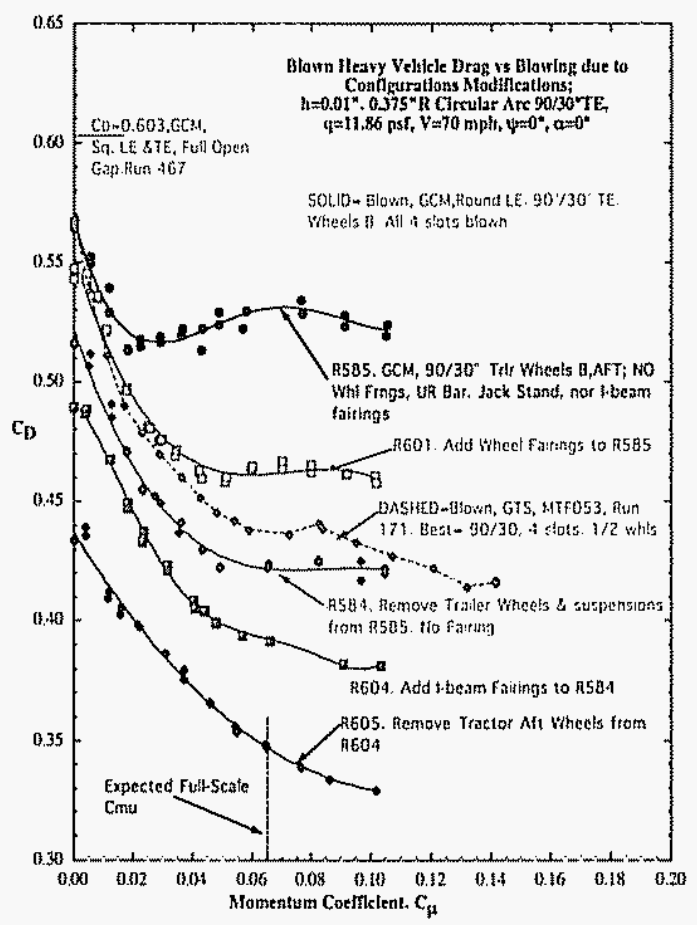

Figure 7- Measured drag reduction due to blowing all 4 slots of various blown configurations

new configuration with all the under-floor disturbance still yields a drag reduction of $24 \%$ below the unblown baseline, Run 467 , at the expected full-scale blowing coefficient of $\mathrm{C} \mu=0.065$. Note however, that 
if the trailer-wheel wake effects were eliminated entirely (Run 584), a drag reduction of $30 \%$ is possible, or even $35 \%$ if the floor I-beams are faired over (Run 604). In the extreme, if the aft tractor wheel effects were eliminated as well (Run 605), drag reduction of $43 \%$ is possible at the design $\mathrm{C} \mu=0.065$. Drag coefficient $C_{D}=0.33$ is possible for this PHV at a slightly higher blowing level-this is on the order of current sports car coupes. The importance of the vehicle undercarriage is very strong. This understanding from these results should be realized as well by other DOE researchers conducting drag reduction efforts on current HVs: it is very important to account for the underbody and wheels of the entire vehicle!

Wheel fairings were tested to cover the trailer suspension, axles and wheels, and thus eliminate many of the undercarriage problems from Fig. 7. Figure 8 shows the drag reductions of this configuration compared to the "stock baseline" HV which has a total drag coefficient $C_{D}=0.702$ at 0 degrees yaw. The blown results, which are due to several variations in slot height, are seen here. Note that all configurations have the same slot height on the top and sides $(\mathrm{h}=0.01$ ", or 0.154 " full scale). The bottom surface slot height is varied here to determine any gains from improving the disturbed lower surface flow by adding more mass flow there, but the total $\mathrm{C} \mu$ is comparable for all configurations. Indeed, it is seen that increasing the lower slot height does reduce $C_{D}$ at the same $C \mu$, but that in the extreme, too large a slot ( $h=0.05$ " on bottom) can reverse this trend. For the $h=0.04$ " bottom slot and 0.01 " on the other three sides, $C_{D}$ is reduced $31 \%$ at $C \mu=0.04-0.05$ relative to the stock baseline configuration. At increased blowing, drag continues to be reduced but at a lesser rate. It is seen that this performance in $\% \mathrm{C}_{\mathrm{p}}$ reduction for the "real-world" PHV configuration is roughly the same as that for our very idealized (smooth bottom, half wheels, no mirrors, etc.) GTS blown truck (Run 171) compared to its generic baseline with $C_{D}=0.627\left(\Delta C_{D}=-30.6 \%\right.$ for the GTS at $C \mu=0.065$ or $\Delta C_{D}=-29.2 \%$ at $C \mu=0.05$ ). Thus this latest windtunnel evaluation has provided a "real-world" configuration that is capable of about $31 \%$ drag reduction, or $15-16 \%$ fuel economy increase at 60 $65 \mathrm{mph}$ highway speeds. These tests also confirmed (see Figure 9 from Reference 7) the ability to provide yawing moment to counteract side winds and also provide directional stability to these large-sided vehicles. Figure 9 shows that the yawing moment due to vehicle side winds of Figure 6 can be offset with very low side blowing rates and no moving surfaces. A valuable lesson from these tests was the considerable interference (separated and reversed flow) effects produced by all the mechanical components and the wheels on the trailer underside.

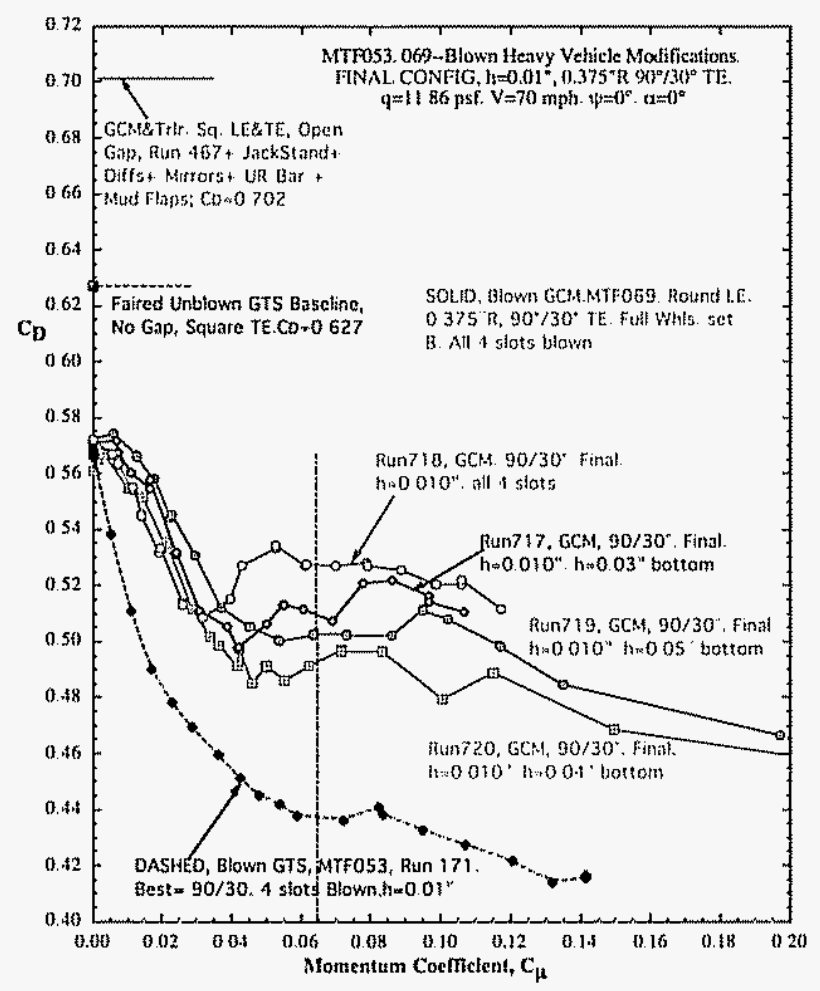

Fig. 8-Drag reduction due to blowing and geometry on the final PHV configuration

One last item of interest from these tests is the additional drag and incremental horsepower required to overcome the protrusions into the flow of the components shown in Table I.

Figure 8 thus represents the drag of this configuration of the full-scale test vehicle, which eliminates the major ones of these component items (under-ride bar and flaps are now enclosed) but still is hampered by the presence of the legally-required rear-view mirrors (although video cameras might eventually be substituted here). We will employ the larger blower blowing slot (from Run 720) because of its more favorable effects (more mas flow) on the underbody flow. 


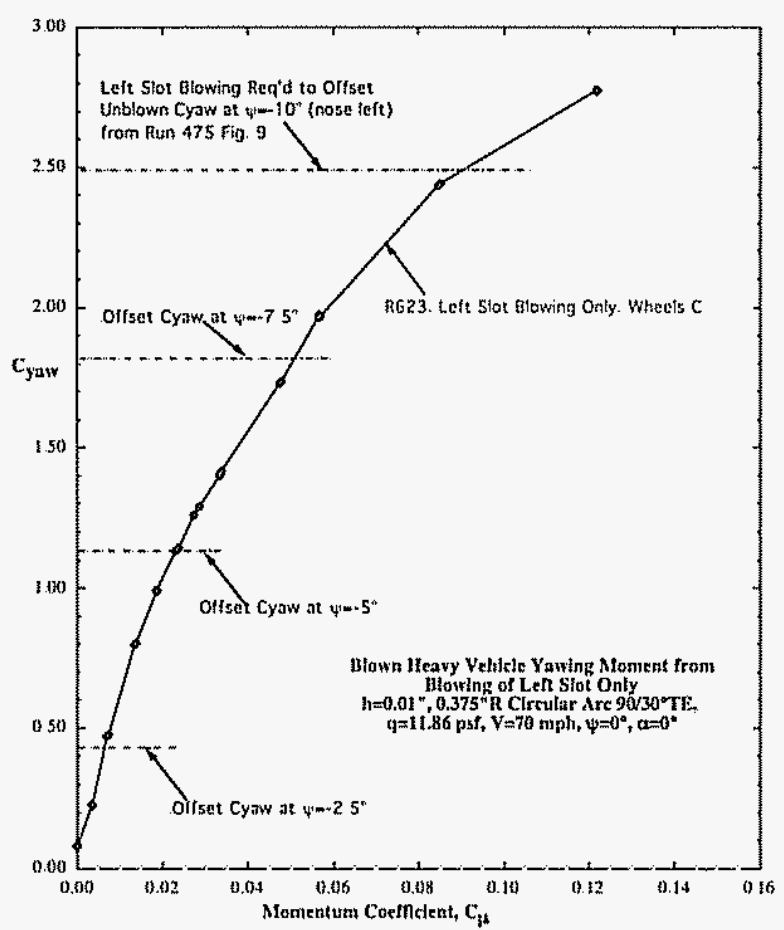

Figure 9- Yawing moment due to blowing left side slot, and required yaw to offset directional instability from Figure 6

\begin{tabular}{|c|c|c|}
\hline Component & $\Delta \mathrm{C}_{\mathrm{D}}$ & $\Delta \mathrm{HP}, 70 \mathrm{mph}$ \\
\hline $\begin{array}{c}\text { Rear View } \\
\text { Mirrors }\end{array}$ & +0.043 & +10.51 \\
\hline Under-ride bar & +0.049 & +11.97 \\
\hline Mud flaps & +0.005 & +1.22 \\
\hline Jack stands (feet) & +0.002 & +0.49 \\
\hline \multicolumn{2}{|c|}{ Tractor } \\
Different'l & +0.001 & +0.24 \\
\hline \\
$\begin{array}{l}\text { Table I- Drag increments and corresponding } \\
\text { Horsepower required due to external } \\
\text { components }\end{array}$
\end{tabular}

\section{UPDATED FULL-SCALE TESTING}

\section{Trailer Modifications}

As a result of the above series of tunnel evaluations and developments, a final blown Pneumatic Heavy Vehicle configuration to undergo fuel economy testing was determined, and includes the following:
- Ninety-degree (vertical side comers) and 30degree (top \& bottom) blowing surfaces with variable slot heights (see Fig. 8)

- 60\% Cab Extender, 16" gap exposed

- Trailer wheel and axle fairings on trailer, and no exposed mud flaps

- Forward trailer wheel location

- Aerodynamic under-ride bar (airfoil fairing)

- Stock wheels, four per axle on trailer

- Stock differentials, axles, and springs on tractor

- Side mirrors on tractor, as required

The trailer modification was completed by GTRI and our teammate prototype shop Novatek, Inc. in early Summer 2004. It is shown at GTRI in Figures 10 and 11. Not shown are the internal blowers connected by ducting to the trailing edge blowing surfaces, nor the small diesel drive motor powering these blowers. Air was entrained into these blowers through the NACA inlets on the trailer sidewalls shown in Figure 10. Preliminary checkout testing was conducted at GTRI to measure internal and jet pressures, temperatures, and flow rates, degree of trailing edge jet turning, and data systems operation. When all systems where confirmed, the PHV trailer was picked up by teammate Volvo Technology of America (VTA) and transported to Volvo's facility in North Carolina.

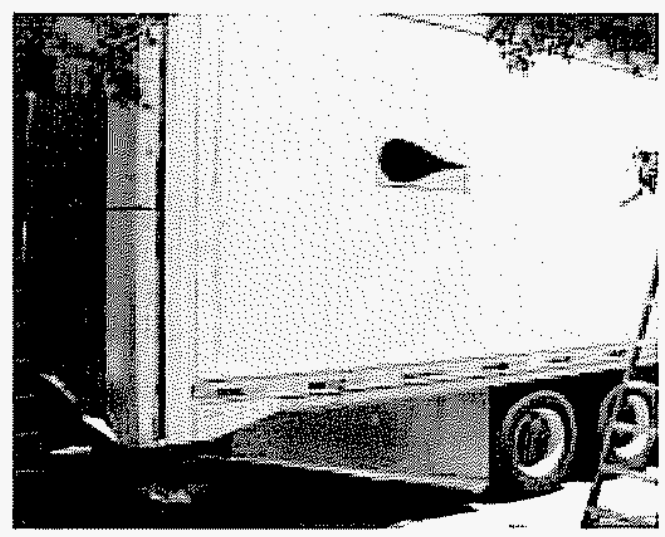

Fig. 10- Assembled PHV trailer at GTRI, showing aft wheel fairing and NACA inlet to blower 


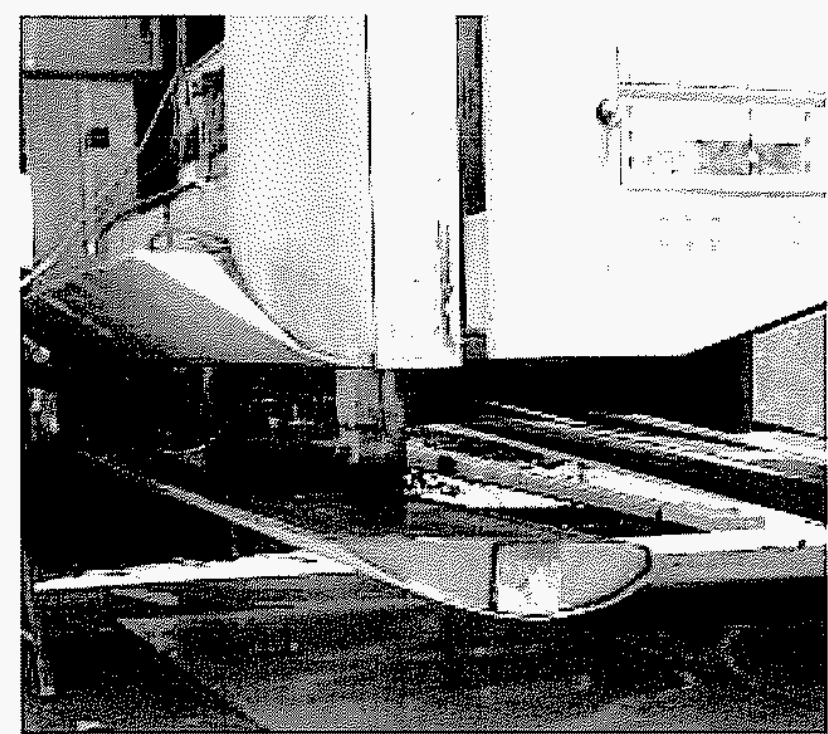

Fig. 11- Faired under-ride bar below aft turning surface on PHV trailer at GTRI

\section{Preliminary Tuning Test 3 (TT3)}

After arrival at the Volvo facility, the test truck was again evaluated statically (parked off road) to assure blowing jet turning, which as Figure 12 shows, was quite satisfactory, especially on the 90-degree vertical surfaces. Tuning Test 3 was then conducted on a four-lane highway (US Route 311 near Greensboro NC) to confirm that all blowing and data systems were operating successfully on-road, and to generate preliminary fuel consumption data prior to the upcoming SAE Type-II test On-road flow field attachment due to jet turning is compared in Figure 13 (blowing ON) and Figure 14 (blowing OFF). These photos give a graphic demonstration of the blowing effectiveness in preventing aftsurface flow separation on the trailer aft corners. A view of the entire PHV test vehicle, including the added $60 \%$ cab extenders and wheel fairings, is seen in Figure 15 .

Although not considered as truly indicative of fuel economy determination, the on-road tuning tests conducted can yield significant trends. To eliminate any side wind effects, they were run in both North/South directions on a 2.9 -mile length of dual-lane highway using an on-board digital fuel readout based on recorded pulses of the Volvo's diesel engine fuel-injection system. Speed was set and maintained by the Volvo cruise control at 65 mph between preset road signposts once the vehicle had achieved test speed, so no accelerations/ decelerations were included. On-board laptop computers recorded truck engine parameters and fuel consumption plus blowing parameters. The data was averaged over the N/S runs to yield each test point (a total of 29 runs were conducted in three

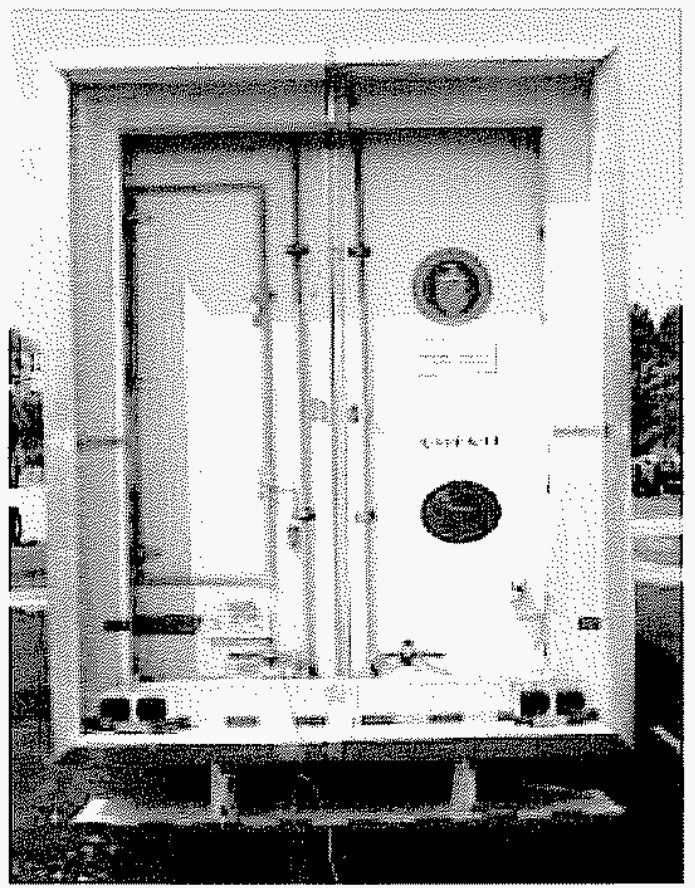

Fig. 12- Static jet evaluation in Volvo lot, showing 90 degree or greater jet turning from side slots

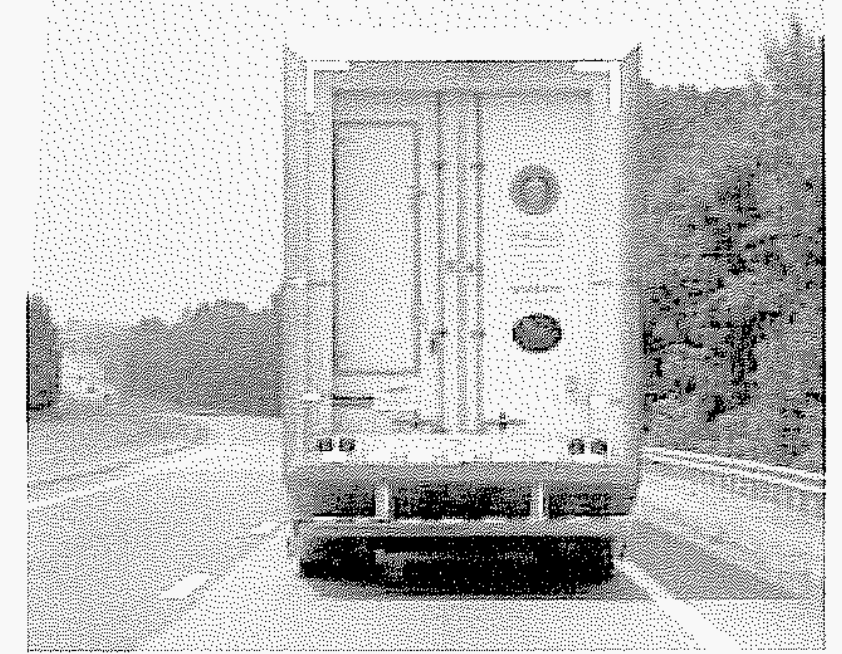

Fig. 13- Orange tuft flow visualization showing flow turning with blowing $\mathrm{ON}$ 


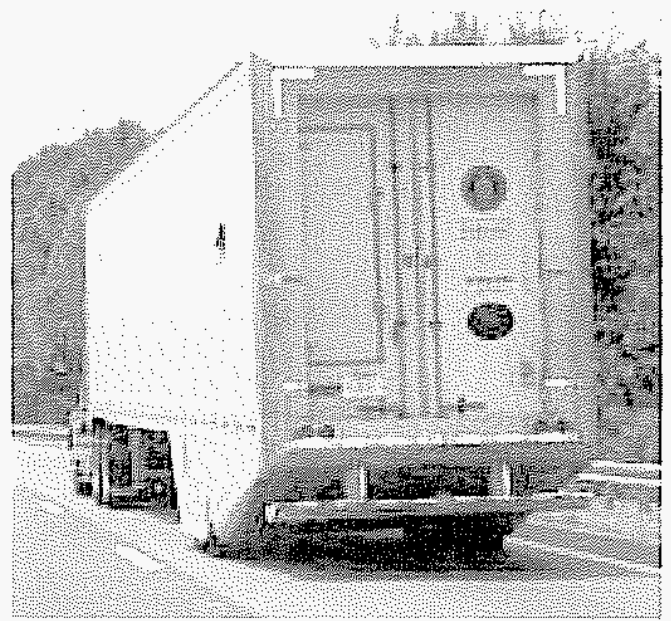

Fig. 14- Flow visualization showing lack of aft flow turning with blowing $O F F$

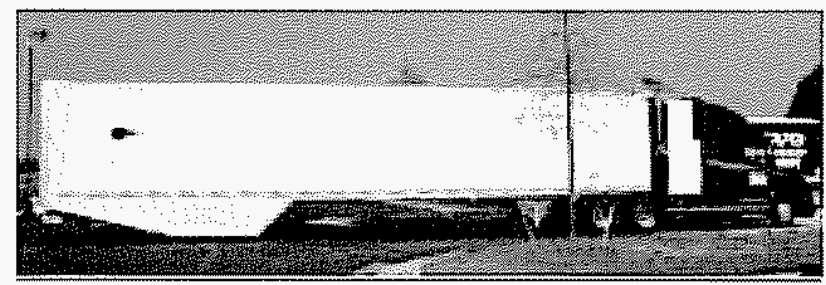

Fig. 15- PHV Test Vehicle prior to road testing

days in August 2004), and then each test condition was repeated at least once for consistency

Fuel economy was then determined in three ways, with the results shown in Figure 16 as functions of blowing coefficient, $\mathrm{C} \mu$. (Data are plotted as percent miles/gallon change from the mpg of the baseline stock trailer, which was also tested.) First, the Volvo in-cab fuel meter was started/stopped as the mileage posts were passed, with the elapsed time-averaged accumulated fuel consumption being read directly by the driver at run's end. This is probably the least reliable and showed some data scatter. At the same time, the engine parameters were recorded digitally and integrated to give timeaveraged mpg, but this was calculated over two different time spans. The first, labeled "VTA time average, short time", was integrated by Volvo engineers over only a short run distance where they figured the tractor engine was appropriately loaded (usually slightly uphill, and normally not downhill). The second, labeled "VTA time averaged, full run range", used the same data but integrated it over the entire 2.9 mile sun, each direction. Although one would expect the short-term uphill data to produce lower fuel economy than the full-distance calculations, it actually produced the highest of the 3 methods in Fig. 16, giving 22-23\% averaged fuel economy increase $(\% \mathrm{FEI})$ at $\mathrm{C} \mu=0.04$, compared to the stock HV rig. Here the results are again averaged if more than one run was conducted at a given test condition. We tend to feel that the full-time average (green bars) may be more consistent and shows less scatter, plus they agree more with the trends of the wind-tunnel data "MTF069 CD" (this tunnel data has been converted to \% mpg increase by assuming that $\% \mathrm{CD}$ reduction is roughly twice the \%fuel economy increase; see Refs. 2, 3, 4). This "fulltime-range" integrated data thus shows the \%fuel economy increase to range from $6-7 \%$ (blowing $\mathrm{OFF}$ ) to $19-20 \%$ (blowing $\mathrm{ON}, \mathrm{C} \mu=0.04$ ), increasing with the blowing rate.

This Tuning Test 3 was thus completed and it confirmed that the PHV test rig was ready for SAE Type-II fuel economy testing.

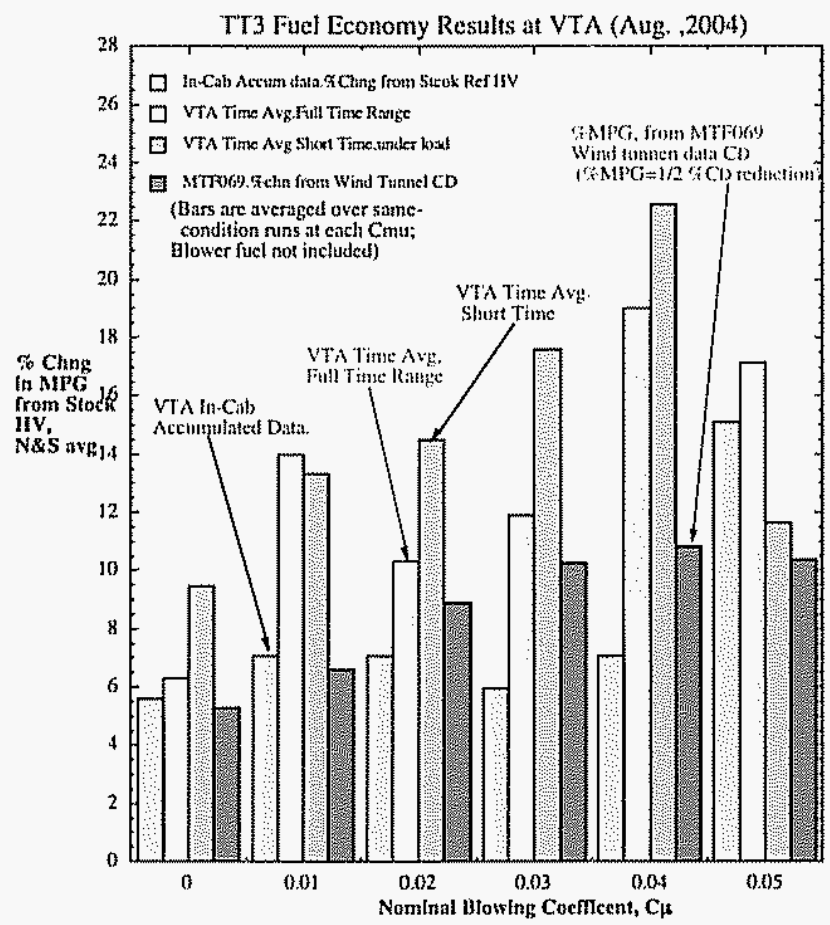

Fig. 16- TT3 Fuel economy results from in-cab instrumentation, Volvo digital data, and windtunnel results 


\section{Phase II of PHV SAE Type-II Tests}

The pneumatic test truck and a stock reference (control) tractor/trailer were transported by Volvo to the Transportation Research Center 7.5-mile test track in East Liberty, $\mathrm{OH}$ for these Phase II SAE Type-II fuel economy evaluations. These were conducted by TRC drivers and personnel strictly in accordance with SAE J1321 procedures, Ref. 8. For one valid test point of fuel consumed, these require that 3 successive runs of 6 laps (45 miles around the TRC test oval) each, at a constant speed and constant blowing parameters or test configurations, be made by the test $(\mathrm{T})$ truck and by the control $(\mathrm{C})$ truck at the same time within certain allowable times and displacement distances. Fuel economy is measured by fuel burned by weighing removable fuel tanks and then ratioing the test truck's fuel used to the control truck's. This eliminates variations in temperature, side winds, etc. When the Test /Control fuel-burned ratio is within a required consistency of each other for 3 measured runs, that data point is considered valid. For this test we intended to run the same PHV rig that had been tested at Volvo during TT3, but hurricane rains during the earlier warm-up laps damaged our cab extenders on the test truck. These were rebuilt and are shown in Fig 17- the geometry is identical to the original. The Control tractor trailer was a second Volvo/Great Dane combo with stock geometry, as shown in Fig. 18.

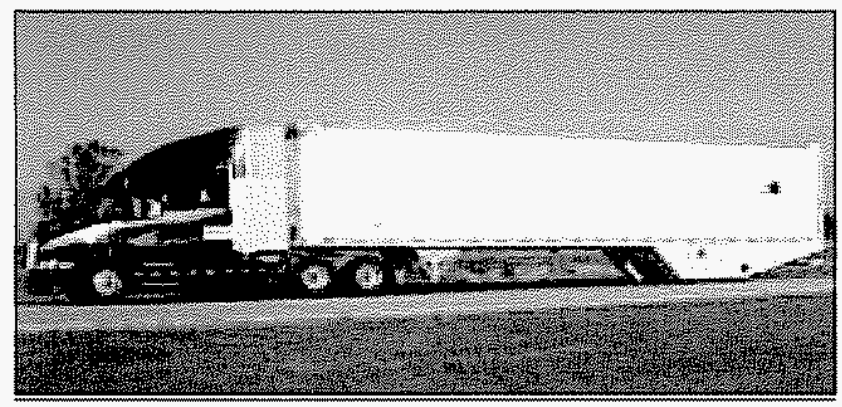

Fig 17- PHV test trailer at TRC with rebuilt cab extenders

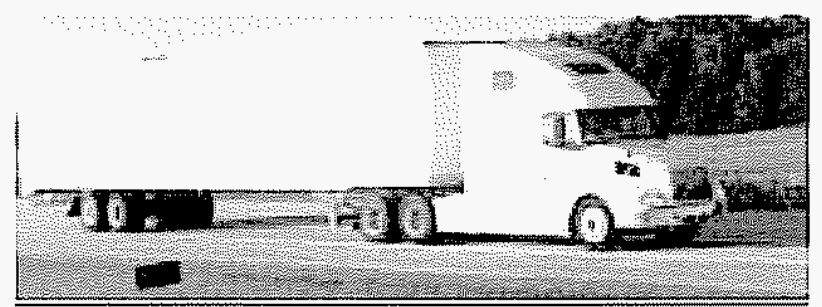

Fig 18- Stock Control (reference) trailer on TRC track

For these data runs, our target data points based on TT 3 and Figure 16 were $\mathrm{C} \mu=0.0,0.02$ and 0.04 at $65 \mathrm{mph}$ speed and $\mathrm{C} \mu=0.0,0.02$, and 0.035 at $75 \mathrm{mph}$. Plus, for comparison to the baseline vehicle, the PHV test truck would be disassembled on-site and returned to the standard (stock) configuration and then run at 65 and $75 \mathrm{mph}$. Each condition required at least three 45 -mile runs on the track. This test program was conducted during 4 days at TRC in September 2004 and required a total of 25 runs, with only one "bad" (inconsistent) run.

The \% Fuel Economy Increase ratios (same as \%MPG change) come from comparing the $\mathrm{T} / \mathrm{C}$ fuel bumed ratios for each test condition to the T/C of the stock baseline truck at the same speed. (Actual mpg was also measured but these are proprietary between Volvo and DOE). These TRC fuel economy increases are seen for two test vehicle speeds in Fig 19 (blue curves), also compared to the TT3 data from Volvo (full-time-range) and the GTRI wind-tunnel data, both from Fig 16. The TRC data fall between the two, but have a very similar trend to both sets conceming increase in \%MPG with blowing $\mathrm{C} \mu$. Considering that there is a $+/-1 \%$ error band in the TRC data, the PHV truck delivers between $6 \%-7 \%$ MPG increase unblown, and $11-12 \%$ increase with blowing at $C \mu=0.02$. Higher blowing than 0.03 seems to cause a slight drop in fuel economy, just as it did in the tunnel data (but at higher $\mathrm{C} \mu$ ), and in the ТT3 data at $\mathrm{C} \mu=0.05$. Again, one would expect that there is still some problem with the lack of flow uniformity underneath the trailer and degradation of the effects of higher blowing (see Fig. 8 as well). However, relative to the previous SAE test on the first generation of this PHV test truck (Refs $3,4,5)$, 
these results are more than double the earlier \%FEI results and 2.5 to 2.8 times the blown results. In neither sets of data is the fuel used to power the blower engine yet included; we are now conducting a recalibration of the electronic small-flow-rate fuel meter installed on that engine and will incorporate those results shortly. Once this is done, it is also possible to consider replacing the relatively large blower engine with alternate sources of lowpressure air supply.

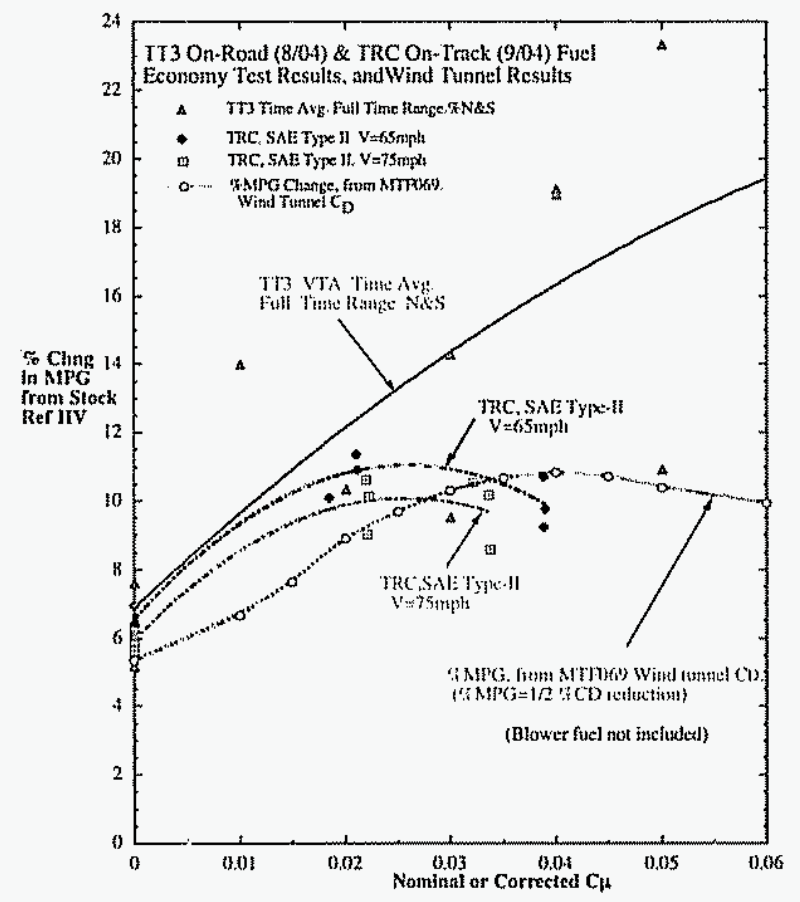

Fig 19- TRC SAE Type-II fuel economy results

There was insufficient funding during the current TRC test to evaluate the effects of each of the geometric components comprising the PHV configuration, but DOE requested that we identify the contribution of the pneumatic devices alone, exclusive of the wheel fairings and cab extenders. The pneumatic effects must by definition include the effects of the rear curved blowing surfaces even before blowing is applied, since these are an integral part of the system. To do this, we employed the wind-tunnel data for this model(Figure 1) to evaluate the drag reductions due to the unblown aft surfaces only, and then used the assumption that $\% \mathrm{FEI}$ is about $1 / 2$ the percentage drag reduction. Figure 20 present this data as the solid blue curves,

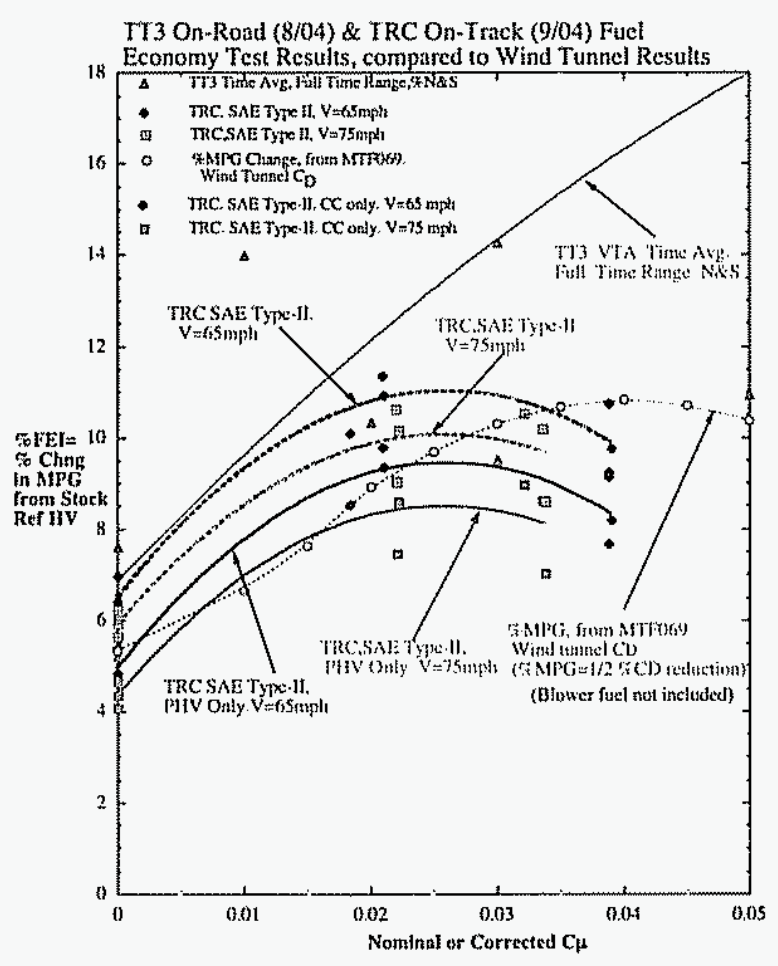

Fig 20 - TRC SAE Type-II fuel economy results for the pneumatic system components

labeled "PHV only". The trends are quite similar to those above, of slightly less magnitude in drag reduction and resulting fuel economy increase.

In neither sets of the above data is the fuel used to power the blower engine included. In the Fig. 21 middle (dashed) curves, we have included blower engine fuel burned, where we have also added the use of pulsed (cyclic) blowing to reduce the blowing mass flow required to achieve these drag reductions (see Ref. 9 for details of this technology which GTRI developed with NASA). Results including this not-yet-optimized system still show approximately $8-9 \% \mathrm{FEI}$ for these blown configurations including blower fuel. Note also in Fig. 21 that the data at the higher speed $(75 \mathrm{mph})$ show greater improvement from blowing than at $65 \mathrm{mph}$ since drag at $75 \mathrm{mph}$ is the more dominant term over rolling resistance. As noted in the figure, the raw TRC data have been equalized to assure that the 


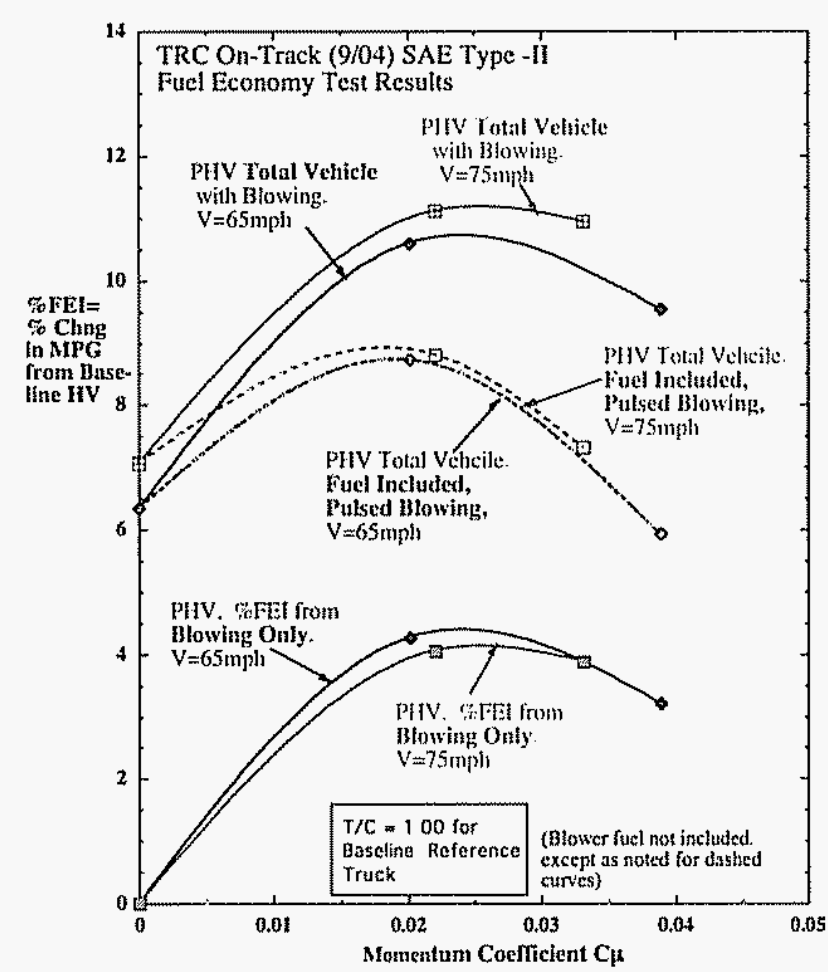

Fig 21 - TRC SAE Type-II fuel economy results for the pneumatic system components

T/C ratios (Test /Control vehicle fuel-burned ratios, see Ref. 8) for the baseline reference configurations (from which the test vehicle fuel economy increases were derived) were the same $(\mathrm{T} / \mathrm{C}=1.0)$ at both speeds.

\section{CONCLUSIONS}

To advance the state of development of pneumatic aerodynamics for improvement of Heavy Vehicle drag reduction, fuel economy, braking, stability and safety of operation, GTRI and its team members have continued in 2004 (FY03 and FY04) our previous program for DOE EERE. We have conducted new model-scale wind-tunnel investigations to identify and correct aerodynamic problems areas of our first fuel-economy test We have then completed new full-scale on-road and test-track fuel economy validations of these advanced capabilities on a full-scale Pneumatic Heavy Vehicle. Results of this recent effort include:
- We have identified the aerodynamic problem areas from our first PHV road test and how to correct these; current wind tunnel data indicate that drag reductions of $30-31 \%$ result from the new PHV configuration with all real-world suspension and geometry components, and fuel economy increases of $15-16 \%$ should result for these new configurations at highway speeds due to blowing and associated geometry improvements. A new blown test vehicle modification was fabricated and assembled based on this wind-tunnel model geometry.

- Preliminary Tuning Tests of the new PHV fullscale test vehicle showed Fuel Economy increases of up to $19-20 \%$ with blowing, as measured from these unofficial fuel economy runs.

- SAE Type-II fuel economy runs of the PHV vehicle on the 7.5-mile TRC test track showed 6-7\% FEI for the unblown truck and 11-12\% FEI for the combined blown vehicle. This represents an increase by a factor of 2.5 to 2.8 in \% FEl compared to the previous Phase I TRC test. When corrected for fuel burned by the non-optimized off-the shelf oversized blower engines, this value was reduced to $8-9 \%$ FEI. For the US HV trucking fleet, this represents 1.8 to 1.9 billion gallons of diesel that could be saved per year by theses improved PHV configurations

- The PHV concept has now been verified both by smaller-scale wind tunnel evaluations of a very realistic model and by full-scale on-road and ontrack SAE testing to be a promising means to reduce drag and increase fuel economy of HVs. Increase in safety of operation from improved braking and increased directional control/stability (plus further reductions in $C_{D}$ ) in side winds waere also indicated by tunnel results. We must still address and resolve the problems caused by undercarriage component protrusion that seem to cause the blowing effectiveness to drop somewhat at higher blowing, as well as integrate an optimized blower drive or other air source into the vehicle.

\section{REFERENCES}

1. Englar, Robert J., "Circulation Control Pneumatic Aerodynamics: Blown Force and Moment Augmentation and Modification; Past, Present and Future," AIAA Paper 2000-2541, Denver, CO, June $19-22,2000$ 
2. Englar, Robert J., "Advanced Aerodynamic Devices to Improve the Performance, Economics, Handling and Safety of Heavy Vehicles," SAE Paper 2001-012072, Washington, DC, May 14-16, 2001.

3. Englar, R J. "Pneumatic Heavy Vehicle Aerodynamic Drag Reduction, Safety Enhancement, and Performance Improvement," in the Proceedings of the UEF Conference on "The Aerodynamics of Heavy Vehicles: Trucks, Buses, and Trains", PacificGrove, CA, Dec. 2-6, 2002.

4. Englar, Robert J. "Drag Reduction, Safety Enhancement and Performance Improvement for Heavy Vehicles and SUVs Using Advanced Pneumatic Aerodynamic Technology", SAE Paper 2003-013378, Ft. Worth, Nov, 10-12, 2003.

5. Diamond, Sidney, "FY2003 Annual Progress Report for Heavy Vehicle Systems Optimization, FreedomCAR and Vehicle Technologies Program", February, 2004

6. Englar, R. J, "Continued Development \& Improvement of Pneumatic Heavy Vehicles, Phase VI, DOE Quarterly Report 7," April 15, 2004

7. Englar, R. J., "Continued Development \& Improvement of Pneumatic Heavy Vehicles, Phase VI, DOE Quarterly Report. 8," July 15, 2004.

8. "Joint TMC/SAE Fuel Consumption Test Procedure-Type-II," SAE J1321, Oct86.

\section{ACKNOWLEDGMENTS}

The author wishes to acknowledge and thank $\mathrm{Dr}_{\text {. }}$ Sidney Diamond, and Dr. Jules Routbort, of DOE for their continued support and encouragement of this work, as well as Mr. Victor Suski for the continued very valuable involvement of the ATA. The technical assistance of Ken Burdges of Novatek, Inc, Skip Yeakel of Volvo, and Charlie Fetz of Great Dane is also greatly appreciated, as are the experimental efforts of GTRI Co-op students Graham Blaylock, Warren Lee, Chris Rabe, Erik Kabo, and Brian Corner from the Georgia Tech School of Aerospace Engineering, researchers Dr. Rob Funk and Paul Habersham of GTRI, plus home-grown student assistants Rob J. Englar and Michael J. Englar

\section{CONTACT}

Robert J. Englar, Principal Research Engineer Georgia Tech Research Institute

Aerospace, Transportation \& Advanced Systems Lab CCRF, Code 0844

Atlanta, GA 30.332-0844

(770) 528-3222, Office

(770) 528-7586, Wind Tunnel

(770) 528-7077, Fax

bob.englar@gtri.gatech.edu 